\title{
Option-Implied Volatility Measures and Stock Return Predictability
}

\author{
$\mathrm{Xi} \mathrm{Fu}^{*} \quad$ Y. Eser Arisoy ${ }^{\dagger}$ \\ Mark B. Shackleton ${ }^{\ddagger}$ \\ Mehmet Umutlu ${ }^{\S}$
}

\begin{abstract}
Using firm-level option and stock data, we examine the predictive ability of option-implied volatility measures proposed by previous studies and recommend the best measure using upto-date data. Portfolio level analysis implies significant non-zero risk-adjusted returns on arbitrage portfolios formed on the call-put implied volatility spread, implied volatility skew, and realized-implied volatility spread. Firm-level cross-sectional regressions show that, the implied volatility skew has the most significant predictive power over various investment horizons. The predictive power persists before and after the 2008 Global Financial Crisis.
\end{abstract}

Key words: option-implied volatility; volatility skew; return predictability

JEL classification: G11; G12

We would like to thank Stephen Figlewski (the Editor) for providing us with extremely insightful comments and constructive suggestions... We thank Ser-Huang Poon, Metteo Sandri, Stephen Taylor, and all participants at 2014 Paris Financial Management Conference, and the New Financial Reality Seminar at the University of Kent for helpful comments.

* Corresponding author. Department of Economics, Finance and Accounting, University of Liverpool Management School, University of Liverpool, Chatham Street, Liverpool L69 7ZH, UK, Tel: +44(0)1517953000, Fax: +44(0)1517949827, Email: Xi.Fu@liverpool.ac.uk.

† DRM Finance (CEREG), Université Paris-Dauphine, PSL Research University, DRM Finance, Place du Maréchal de Lattre de Tassigny, 75016775 Paris-Cedex 16, France, Tel: +33(0)144054360, Email: eser.arisoy@dauphine.fr.

${ }^{\ddagger}$ Department of Accounting and Finance, Lancaster University Management School, Lancaster LA1 4YX, UK, Tel: +44(0)1524594131, Email: m.shackleton@lancaster.ac.uk.

$\S$ Department of International Trade and Finance, Yasar University, Bornova, 35100, Izmir, Turkey, Tel: +90(0)2324115195, Email: mehmet.umutlu@yasar.edu.tr. 


\section{Introduction}

Options are forward-looking instruments and option-implied measures contain valuable information regarding investors’ expectations about the return process of the underlying asset. Option-implied volatility has received particular attention due to the time-varying property of volatility which is a widely used parameter in asset pricing. It is well-documented that implied volatility extracted from option prices provides good forecasts of future volatility. ${ }^{1}$ In a similar vein, recent studies examine the predictive ability of different option-implied volatility measures in the cross-section of stock returns. However, despite growing literature, there is no clear understanding of i) whether different option-implied volatility measures capture distinct information about the volatility curve, ii) which measures are important for investors in predicting stock returns, and iii) which measures would outperform in predicting stock returns in dynamically managed portfolios. By comparing the predictive ability of alternative option-implied volatility measures proposed in the literature, in the context of return predictability, this study highlights whether the proposed option-implied volatility measures are fundamentally different to each other and whether their predictive ability differs by investment horizon. ${ }^{2}$

The relationship between option-implied volatility and stock return predictability is of recent interest. ${ }^{3}$ For example, An, Ang, Bali and Cakici (2014) focus on the implied volatility of individual options and document the significant predictive power of implied volatility in

\footnotetext{
${ }^{1}$ See Christensen and Prabhala (1998), Szakmary, Ors, Kim and Davidson (2003), Poon and Granger (2005), Kang, Kim and Yoon (2010), Taylor, Yadav and Zhang (2010), Yu, Lui and Wang (2010), and Muzzioli (2011) for studies on the predictive ability of option-implied volatility on future volatility.

${ }^{2}$ The option-implied volatility measures used in this study are: the call-put implied volatility spread (CPIV ), the implied volatility skew ( IVSKEW ), the "above-minus-below" ( AMB ), the "out-minus-at" of calls (COMA), the "out-minus-at" of puts ( POMA), and the realized-implied volatility spread ( RVIV ). Details about these measures can be found in Section 2.2.

${ }^{3}$ For example, Arisoy (2014) use returns on crash-neutral ATM straddles of the S\&P 500 index as a proxy of the volatility risk, and returns on OTM puts of the S\&P 500 index as a proxy of the jump risk, and find that the sensitivity of stock returns to innovations in aggregate volatility and market jump risk can explain the differences between returns on small and value stocks and returns on big and growth stocks. Doran, Peterson and Tarrant (2007) find supportive evidence that there is predictive information content within the volatility skew for short-term horizon.
} 
predicting individual stock returns. More specifically, large increases in call (put) implied volatilities are followed by increases (decreases) in one-month ahead stock returns. Bali and Hovakimian (2009) investigate whether realized and implied volatilities can explain the cross-section of monthly stock returns and document that there is a positive relationship between the call-put implied volatility spread and one-month ahead stock returns. Cremers and Weinbaum (2010) focus on the predictive power of the call-put implied volatility spread and provide evidence that this measure predicts weekly returns to a greater extent for firms facing a more asymmetric informational environment.

Meanwhile, motivated by the empirically documented volatility skew for equity options, several studies examine the predictive power of information captured by options with different moneyness levels. ${ }^{4}$ For example, Xing, Zhang and Zhao (2010) examine the implied volatility skew, which is the difference between out-of-the-money put and at-the-money call implied volatilities, and find a significantly negative coefficient on the implied volatility skew in Fama-MacBeth cross-sectional regressions. Baltussen, Grient, Groot, Hennink and Zhou (2012) include four different implied volatility measures in their study: out-of-money volatility skew (i.e., implied volatility skew in Xing, Zhang and Zhao, 2010), realized versus implied volatility spread, at-the-money volatility skew (i.e., the difference between the at-themoney put and call implied volatilities), and weekly changes of at-the-money volatility skew. By analyzing weekly stock returns, they find negative relationships between weekly returns and four option-implied measures. In addition to two common factors used in previous studies (at-the-money call-put implied volatility spread and out-of-money implied volatility skew), Doran and Krieger (2010) construct three other measures based on implied volatility extracted from call and put options. These three measures are “above-minus-below”, “out-

\footnotetext{
${ }^{4}$ The phenomenon that the implied volatility of equity options with low strike prices (such as deep out-of-themoney puts or deep in-the-money calls) is higher than that of equity options with high strike prices (such as deep in-the-money puts or deep out-of-the-money calls) is known as volatility skew (Hull, 2012). The volatility skew is widely observed for equity options (Bollen and Whaley, 2004; Bates, 2003; Gârleanu, Pedersen, and Poteshman, 2007; and Xing, Zhang and Zhao, 2010).
} 
minus-at" of calls, and "out-minus-at" of puts. ${ }^{5}$ Results in their study show that differences between at-the-money call and put implied volatilities and those between out-of-the-money and at-the-money put implied volatilities both capture information about future equity returns.

From these studies, it is not clear whether separately constructed option-implied volatility measures in the literature capture fundamentally different information in predicting stock returns. In the presence of other volatility measures, some of these volatility measures may be redundant in predicting stock returns. Building on aforementioned studies, this paper compares the ability of the various option-implied volatility measures to predict one-week to three-month ahead returns. Addressing the question of which option-implied volatility measure(s) outperforms alternatives in predicting stock returns and whether their predictive ability persists over different investment horizons is crucial, having implications for portfolio managers and market participants. These groups can adjust their trading strategies and form portfolios based on option-implied volatility measure(s) that has the strongest predictive power and thus earn excess returns.

To compare the predictive power of option-implied volatility measures, we first form quintile portfolios sorted with respect to six option-implied volatility measures: the call-put implied volatility spread ( CPIV), the implied volatility skew ( IVSKEW ), the "above-minusbelow" ( $A M B)$, the "out-minus-at” of calls (COMA), the "out-minus-at” of puts (POMA), and the realized-implied volatility spread ( $R V I V)$. Then, we construct zero-cost arbitrage portfolios by taking a long position in portfolios with the highest implied volatility measure and a short position in portfolios with the lowest implied volatility measure. The arbitrage portfolio will have significantly non-zero return if there is a statistically significant

\footnotetext{
${ }^{5}$ The "above-minus-below" is the difference between the mean implied volatility of in-the-money puts and outof-the-money calls and the mean implied volatility of in-the-money calls and out-of-the-money puts. "Outminus-at" of calls (puts) is the difference between the mean implied volatility of out-of-the-money calls (puts) and the mean implied volatility of at-the-money calls (puts).
} 
relationship between stock returns and the corresponding option-implied volatility measure. However, portfolio level analysis might suffer from the aggregation effect due to omission of useful information in the cross-section because it does not control for the effects of other option-implied volatility measures and firm-specific effects simultaneously. Consequently, we further perform firm-level cross-sectional regressions to assess the predictive power of all six interlinked option-implied volatility measures.

Our study contributes to the literature in several aspects. First, this study compares the predictive ability of six different implied volatility measures. To the best of our knowledge, this is the most comprehensive study that compares the predictive power of option-implied volatility measures. Secondly, our study tests the predictive power of different option-implied volatility measures on stock returns over various investment horizons. This helps investors better understand the informational content captured by different option-implied volatility measures. Finally, the sample period, from 1996 until 2014, is longer than those used in previous studies. This enables us to analyze whether the predictive power of option-implied volatility measures documented previously is still significant in extended periods using recent data in the US markets.

The paper is organized as follows. Section 2 discusses the data and the methodology. Section 3 examines the relationship between expected stock returns and different optionimplied volatility measures through portfolio level analysis and firm-level cross-sectional regressions. Section 4 discusses potential reasons for the predictive power of option-implied volatility measures through discussions on informed trading, skewness preference, constraints on short-sale, and delta hedging. Section 5 offers concluding remarks. 


\section{Data and Methodology}

\subsection{Data Sources}

Our data come from several different sources. Financial statement data are downloaded from Compustat, monthly and daily stock return data are from CRSP, and option implied volatility data are from OptionMetrics. The factors in Fama-French (1993) three-factor model (i.e., $M K T$, SMB, and $H M L$ ) are obtained from Kenneth French’s online data library. ${ }^{6}$

To distinguish at-the-money options, we follow the criteria in Bali and Hovakimian (2009). ${ }^{7}$ That is, if the absolute value of the natural logarithm of the ratio of the stock price to the exercise price is smaller than 0.1 , an option is denoted at-the-money. We denote options with the natural logarithm of the ratio of the stock price to the exercise price smaller than -0.1 as out-of-the-money call (in-the-money put) options. Options with the natural logarithm of the ratio of the stock price to the exercise price larger than 0.1 are denoted in-the-money call (out-of-the-money put) options. Then, we calculate the average implied volatilities for different kinds of options across all eligible options at the end of each calendar month. Our sample period starts from January 1996 and ends in December 2014 (i.e., 19 years). ${ }^{8}$

\subsection{Option-Implied Volatility Measures}

For equity options, it is normal to observe the existence of volatility skew (i.e., the volatility decreases as the strike price increases). As discussed in the previous section, empirical studies document that a different part of the volatility curve can capture relevant

${ }^{6}$ Available at: http://mba.tuck.dartmouth.edu/pages/faculty/ken.french/data_library.html.

${ }^{7}$ Only stock data for ordinary common shares (CRSP share codes 10 and 11) are retained. Furthermore, closedend funds, REITs (SIC codes 6720-6730 and 6798) and those companies whose shares were trading less than \$5 are excluded. For option data, we focus on the last trading day of each calendar month. We only retain stock options with days-to-maturity greater than 30 but less than 91 days. After deleting options with zero open interest or zero best bid prices and those with missing implied volatility, we further exclude options whose bidask spread exceeds $50 \%$ of the average of the bid and ask prices and options which are traded for less than $\$ 0.25$. ${ }^{8}$ The first observation of the implied volatility is available at the end of January, 1996. So the return observation starts from February, 1996. The last observation of monthly stock returns is the return in December, 2014. Since this study uses three-month holding period return, the last observation for three-month return should be the return during the period from October, 2014 to December, 2014, whereas the last observation for each volatility measure is constructed at the end of September 2014. So the sample consists of 225 monthly observations. The sample size is discussed in detail in section 3.1. 
information about future stock returns (Bali and Hovakimian, 2009; Baltussen et al., 2012; Cremers and Weinbaum, 2010; Xing, Zhang and Zhao, 2010; Doran and Krieger, 2010; etc.). In following subsections, we discuss how different option-implied volatility measures reflect investors’ expectations about future market conditions.

\subsubsection{Call-Put Implied Volatility Spread}

Drawing upon the method documented in Bali and Hovakimian (2009), CPIV is constructed as follows:

$$
C P I V=I V_{\text {ATM , call }}-I V_{\text {ATM, put }}
$$

where $C P I V$ is the call-put implied volatility spread, $I V_{A T M \text {,call }}$ is the average of implied volatilities extracted from all at-the-money call options, and $I V_{\text {ATM,put }}$ is the average of implied volatilities extracted from all at-the-money put options available on the last trading day in each calendar month.

If investors expect decreases in underlying asset prices in the near future, they will choose to buy put options and sell call options. In this case, prices of put options will increase while prices of call options will decrease, suggesting higher implied volatilities for put options and lower implied volatilities for call options. A more negative CPIV predicts decreases in underlying asset prices (i.e., more negative returns) and vice versa. Thus, it is expected that future asset returns should be positively correlated with $C P I V$.

\subsubsection{Implied Volatility Skew}

To construct IVSKEW proposed by Xing, Zhang and Zhao (2010), we calculate the difference between the average of implied volatilities extracted from out-of-the-money put options and the average of implied volatilities extracted from at-the-money call options:

$$
\text { IVSKEW }=I V_{\text {ОTM,put }}-I V_{\text {ATM, call }}
$$


where IVSKEW is the implied volatility skew, $I V_{\text {Отм,риt }}$ is the average of implied volatilities extracted from out-of-the-money put options at the end of each calendar month.

If investors expect that there will be a downward movement in underlying asset price, they will choose to buy out-of-the-money put options. An increase in the demand for out-ofthe-money put options further leads to increases in their prices, and thus in their implied volatilities. In this case, the spread between out-of-the-money put implied volatilities and atthe-money call implied volatilities will become larger. IVSKEW reflects investor's concern about future downward movements in underlying asset prices. A higher IVSKEW indicates a higher probability of large negative jumps in underlying asset prices. So, IVSKEW is expected to be negatively related to future returns on underlying assets.

\subsubsection{Above-Minus-Below}

$A M B$ represents the difference between average implied volatility of options whose strike prices are above current underlying price and average implied volatility of options whose strike prices are below current underlying price. Following Doran and Krieger (2010), this study defines $A M B$ as:

$$
A M B=\frac{\left(I V_{\text {ITM,put }}+I V_{\text {OTM ,call }}\right)-\left(I V_{\text {ITM,call }}+I V_{\text {OTM }, \text { put }}\right)}{2}
$$

where $I V_{\text {ITM,put }}$, IV ОTM,call,$I V_{\text {ITM,call }}$, and $I V_{\text {ОTM,put }}$ are mean implied volatilities of all in-themoney put options, all out-of-the-money call options, all in-the-money call options, and all out-of-the-money put options, respectively.

The variable $A M B$ captures the difference between the average implied volatilities of low-strike-price options and the average implied volatilities of high-strike-price options. Thus, $A M B$ captures the volatility curve asymmetry by investigating both of its tails. More (less) negative values of $A M B$ are indications of more trading of pessimistic (optimistic) investors and thus lower (higher) future stock returns are expected. 


\subsubsection{Out-Minus-At}

Doran and Krieger (2010) also introduce two other measures, which capture the difference between out-of-the-money and at-the-money implied volatilities of call/put options.

$$
\begin{aligned}
& C O M A=I V_{\text {OTM,call }}-I V_{\text {ATM,call }} \\
& P O M A=I V_{\text {OTM }, \text { put }}-I V_{\text {ATM }, \text { put }}
\end{aligned}
$$

All measures in these two equations have the same meanings as in the previous equations (1) $-(3)$.

In contrast to $A M B, C O M A$ ( $P O M A$ ) use only out-of-the-money and at-the-money call (put) options to capture the volatility curve asymmetry. In the option market, it is observed that out-of-the-money and at-the-money call and put options are the most liquid and heavily traded whereas in-the-money options are not traded much (Bates, 2000). It is also reported that bullish traders generally buy out-of-the-money calls while bearish traders buy out-of-themoney puts (Gemmill, 1996). To follow a trading strategy based on volatility curve asymmetry, it is more convenient to construct a measure using the most liquid options for which data availability is not a concern. Positive COMA is associated with bullish expectations, indicating an increase in the trading of optimistic investors. However, a positive POMA reflects the overpricing of out-of-the-money puts relative to at-the-money puts due to increased demand for out-of-the-money puts that provide hedging against negative jump risk.

\subsubsection{Realized-Implied Volatility Spread}

In the spirit of Bali and Hovakimian (2009), we calculate realized volatility ( $R V$ ), which is the annualized standard deviation of daily returns over the previous month, and then construct a realized-implied volatility spread, $R V I V$, as follows:

$$
R V I V=R V-I V_{A T M}
$$

where $I V_{\text {ATM }}$ is the average implied volatility of at-the-money call and put options. 
The variable $R V I V$ is related to volatility risk, which has been widely tested in empirical papers. When testing the volatility risk premium, previous articles focus on the difference between realized volatility and implied volatility (proxied by a variance swap rate). However, rather than using a variance swap rate (which is calculated by using options with different moneyness levels), we focus on at-the-money implied volatility (a standard deviation measure).

\subsubsection{Discussion on Option-Implied Volatility Measures}

To better show that various option-implied volatility measures capture different information about the volatility curve, Exhibit 1 plots call and put implied volatilities of Adobe System Inc. on December 29, 2000. Options included in this Exhibit have an expiration date of February 17, 2001 (i.e., two months ahead).

\section{[Insert Exhibit 1 here]}

From this exhibit, it is clear that CPIV captures the middle of the volatility curve, which reflects small deviations from put-call parity. IVSKEW reflects the left of the put volatility curve and the middle of the call volatility curve. The $A M B$ measure captures the tails of the volatility curve. COMA captures the right side and middle of the volatility curve for call options, while POMA captures the left side and middle of the volatility curve for put options.

From call and put options with the same strike price and time-to-expiration, it is easy to observe small deviations from put-call parity. That is, small differences between paired call and put implied volatilities are apparent. However, these deviations do not necessarily indicate arbitrage opportunities (discussed in Section 4.5). Furthermore, measures IVSKEW , AMB , COMA and POMA provide some indications about the shape of the implied volatility curve. Lower $A M B$ and COMA indicate more negatively skewed implied volatility curves. 
Lower POMA and IVSKEW indicate less negatively skewed implied volatility curves. ${ }^{9}$ Thus, we expect to observe a positive relationship between $A M B$ or COMA and stock returns, but a negative relationship between IVSKEW or POMA and stock returns.

Overall, CPIV , IVSKEW , AMB , COMA and POMA capture different parts of the volatility curve. Therefore it is interesting to test whether these measures (i.e., different parts of the volatility curve) have different predictive ability for asset returns. Taken together, all five option-implied volatility measures capture much of the information contained in the cross-section of implied volatilities (Doran and Krieger, 2010). However, some of them are interdependent, e.g., IVSKEW $=P O M A-C P I V$. So, these three measures cannot be included in the same model because of the multi-collinearity problem. In addition to these measures, we further include another volatility measure used in Bali and Hovakimian (2009), RVIV .

\subsection{Firm Specific Variables}

In order to see whether option-implied volatility measures can predict stock returns after controlling for known firm-specific effects, we also include several firm-level control variables. To control for the size effect documented by Banz (1981), we use the natural logarithm of a company's market capitalization (in thousands of USD) on the last trading day of each month. Following Fama and French (1992), we use the book-to-market ratio as another firm-level control variable. Jegadeesh and Titman (1993) document the existence of a momentum effect (i.e., past winners, on average, outperform past losers in short future periods). We use past one-month returns to capture the momentum effect. Stock trading volumes are included as another variable (measured in hundred millions of shares traded in the previous month). The market beta reflects the historical systematic risk and is calculated by using daily returns available in the previous month using the standard CAPM

\footnotetext{
${ }^{9}$ Compared to POMA, IVSKEW uses at-the-money call options, which are more liquid than at-the-money put options and are seen as the investors' consensus on the firm’s uncertainty (Xing, Zhang, and Zhao, 2010).
} 
framework. ${ }^{10}$ The bid-ask spread is used to control for liquidity risk. It is defined as the mean daily percentage bid-ask spread over the previous month where the percentage bid-ask spread is the difference between ask and bid prices scaled by the mean of the bid and ask prices (Bali and Hovakimian, 2009). Finally, we also control for option trading volume (measured in millions of options traded in the previous month), which is documented to contain information about future stock prices. ${ }^{11}$

\section{Results}

\subsection{Descriptive Results}

Exhibit 2 presents some descriptive statistics, such as mean, standard deviation, minimum, $5^{\text {th }}$ percentile, $25^{\text {th }}$ percentile, median, $75^{\text {th }}$ percentile, $95^{\text {th }}$ percentile and maximum of each volatility measure, sample size available for each measure, as well as pairwise correlations. ${ }^{12}$

\section{[Insert Exhibit 2 here]}

On the basis of all available observations on the last trading day of each month during the sample period, Panel A of Exhibit 2 reports descriptive statistics for option-implied volatility measures. Therefore, the sample size varies for each measure. It is observed that CPIV , AMB , COMA and RVIV have negative means, while those for IVSKEW and POMA are positive. The last column of Panel A shows that, the sample size for CPIV is largest (i.e., 230,884), whereas the sample size for $A M B$ is smallest (i.e., 66,104). CPIV is constructed by using near-the-money call and put options while $A M B$ is constructed by using deep out-of-the-money and in-the-money call and put options. It is expected that more

\footnotetext{
${ }^{10}$ It is required that stocks should have more than 15 daily observations in the previous month for beta calculation.

${ }^{11}$ Pan and Poteshman (2006) find strong evidence that option trading volume contains information about future stock prices. Doran, Perterson, and Tarrant (2007) incorporate option trading volume when analyzing whether the shape of implied volatility skew can predict the probability of a market crash or spike.

${ }^{12}$ The option-implied volatility measures in Exhibit 2 are reported in decimals, not in percentages. The full sample presented in Panel A consists of 4,999 US firms, and the intersection sample in Panel B consists of 3,317 US firms.
} 
near-the-money options are available than deep out-of-the-money and in-the-money options. So the larger sample size for $C P I V$ and the much smaller sample size for $A M B$ are reasonable.

Panel B of Exhibit 2 reports the descriptive statistics of the intersection sample which consists of stocks with all option-implied volatility measures available. The intersection sample has 62,562 stock-month observations. ${ }^{13}$ CPIV , AMB , COMA and RVIV have negative means, whereas IVSKEW and POMA have positive means. The negative sample mean of $C P I V$ shows that put options on individual companies tend to have higher average implied volatility than calls. Individual firms tend to have negative implied volatility skew as seen by the positive sample means of POMA and IVSKEW and negative sample means of $A M B$ and COMA. These results support the view that, on average, implied volatility curve is asymmetric for individual equities as observed in Exhibit 1.

As discussed in Section 2.2, IVSKEW is the difference between POMA and CPIV . On average, 15.98 percent of the value of the negative skew stems from the difference between at-the-money implied volatility of puts and at-the-money implied volatility of calls, and the other 84.02 percent can be due to the difference between out-of-the-money implied volatility and at-the-money implied volatility of puts. Given the positive relationship between stock returns and CPIV and the negative relationship between stocks returns and IVSKEW documented in previous studies (Bali and Hovakimian, 2009; Cremers and Weinbaum, 2010; Doran and Krieger, 2010; and Xing, Zhang, and Zhao, 2010), we infer whether or not POMA (which represents the left-hand side of the put implied volatility curve) plays a significant role in predicting stock returns. If there is no empirical evidence in favor of significant predictive ability for POMA, the predictive power of IVSKEW should be driven by the

\footnotetext{
${ }^{13}$ The intersection sample in Doran and Krieger (2010) consists of 62,076 company months during the period from January 1996 to September 2008. Thus, the size of our intersection sample during the same period is smaller than that of Doran and Krieger (2010). This can be due to the different moneyness criteria and more control variables used in this study.
} 
difference between at-the-money put implied volatilities and the at-the-money call implied volatilities.

Panel C of Exhibit 2 presents pairwise correlations; there are four high average correlations. The correlation between CPIV and IVSKEW is -0.6580 , the correlation between IVSKEW and POMA is 0.7333, the correlation between AMB and COMA is 0.6678, and the correlation between $A M B$ and $P O M A$ is -0.6842 . Other pairwise correlations are relatively low. These high correlations indicate that there might be some information overlap in option-implied measures. By trying to avoid overlap, this study takes into account potential multicollinearity problem when conducting multivariate firm-level cross-sectional regressions.

\subsection{Portfolio Level Analysis}

In order to examine the relationship between quintile portfolio returns and each volatility measure, we construct quintile portfolios, and further form a "5-1" arbitrage portfolio within the full sample by holding a long position on the quintile portfolio with the highest volatility measure and a short position on the quintile portfolio with the lowest volatility measure. Then, we test the null hypothesis that the "5-1" arbitrage portfolio has a mean return equal to zero. If the average return on the " $5-1$ " arbitrage portfolio is significantly positive (negative), there is a positive (negative) relationship between the volatility measure and portfolio returns. Results for portfolio level analysis are presented in Exhibit 3.

\section{[Insert Exhibit 3 here]}

We first examine the effect of CPIV on subsequent one-month portfolio returns. For both equally-weighted and value-weighted portfolios, returns increase monotonically from portfolios with the lowest CPIV to portfolios with the highest CPIV. The mean return on the equally-weighted " $5-1$ ” arbitrage portfolio is $1.12 \%$ per month (with a p-value close to 0 ), and the mean return on the value-weighted " $5-1$ " arbitrage portfolio is $0.97 \%$ per month (with 
a p-value of 0.0002). Significant positive mean returns on "5-1" arbitrage portfolios indicate a positive relationship between $C P I V$ and portfolio returns. We also control for FamaFrench risk factors to examine whether there are risk-adjusted return differences for arbitrage portfolios. Results are consistent with those obtained for raw return differences. Jensen's alpha with respect to Fama-French three-factor model is $1.16 \%$ per month (with a p-value close to 0 ) for equally-weighted " $5-1$ " arbitrage portfolios and it is $1.10 \%$ per month (with a p-value of 0.0001 ) for value-weighted “5-1" arbitrage portfolios. These results for CPIV are comparable with the results in Bali and Hovakimian (2009). Bali and Hovakimian (2009) document that the equally-weighted (value-weighted) raw return on the arbitrage portfolio is, on average, $1.425 \%(1.045 \%)$ per month with a t-statistic of 7.9 (4.2) and the equallyweighted (value-weighted) Jensen's alpha on the arbitrage portfolio is $1.486 \%$ (1.140\%) with a t-statistic of 8.6 (4.5).

Next, we focus on the effect of IVSKEW . The results in Exhibit 3 show a monotonic decreasing pattern in equally- and value-weighted portfolio returns. Portfolios with lower IVSKEW outperform those with higher IVSKEW . Average monthly returns on "5-1" equally-weighted and value-weighted arbitrage portfolios are always negative and statistically significant at a $5 \%$ level $(-0.86 \%$ with a p-value close to 0 and $-0.64 \%$ with a pvalue of 0.0133 , respectively). The negative relationship between IVSKEW and portfolio return is still significant after controlling for market excess returns ( $M K T$ ), size ( $S M B)$ and book-to-market ratio ( $H M L)$.

Exhibit 3 shows weak evidence for a negative relationship between $A M B$ and portfolio returns. For equally-weighted “5-1” arbitrage portfolio, Jensen’s alpha with respect to FamaFrench three-factor model is $-0.44 \%$ per month, which is marginally significant at a $10 \%$ level. 
Exhibit 3 also presents quintile portfolio level analysis results for two "out-minus-at" measures. For both COMA and POMA, there is no evidence on-of thea relationship between these two measures and one-month ahead asset returns (the average monthly return and Jensen's alpha with respect to Fama-French three-factor models on each "5-1" arbitrage portfolio are not significantly non-zero).

Finally, results in Exhibit 3 confirm a negative relationship between $R V I V$ and onemonth ahead portfolio returns. Both the average return and the Jensen's alpha decrease monotonically from the portfolio with the lowest $R V I V$ to that with the highest $R V I V$. Such a negative relationship is always significant at a $5 \%$ level no matter whether the return is riskadjusted or not. For example, Jensen’s alpha for an equally-weighted “5-1” arbitrage portfolio is $-0.57 \%$ per month with a p-value of 0.0007 and that for value-weighted " $5-1$ " arbitrage portfolio is $-0.64 \%$ per month with a p-value of 0.0039 . These results are broadly comparable to results in Bali and Hovakimian (2009). They document that Jensen's alpha for the arbitrage portfolio constructed on $R V I V$ is $-0.587 \%$ with a significant t-statistic of -2.5 when using the equally-weighted scheme, and $-0.642 \%$ with a significant t-statistic of -2.2 when using the value-weighted scheme.

To summarize, results in Exhibit 3 confirm that $C P I V$ is positively related to onemonth ahead portfolio returns, whereas IVSKEW and RVIV are negatively related. Exhibit 3 also provides weak evidence about the negative relationship between $A M B$ and portfolio returns. However, through portfolio level analysis, COMA and POMA do not have significant power to explain one-month ahead portfolio returns.

Although portfolio level analysis helps determine potential candidates among several option-implied volatility measures in predicting future returns, it does not allow us to control for firm-specific effects. Some other firm-specific effects may also play a role in explaining 
stock returns. To address this issue, we perform firm-level cross-sectional regressions in the following subsection.

\subsection{Firm-Level Cross-Sectional Regression Results}

This subsection provides results from firm-level cross-sectional regressions with firmspecific control variables (i.e., size, book-to-market ratio, previous one-month return, stock trading volume, historical beta, bid-ask spread, and option trading volume). In the first step of the firm-level cross-sectional regressions, at the end of each calendar month, stock returns of different firms are regressed on explanatory variables (e.g., option-implied volatility measures and control variables) cross-sectionally. Thus, during the full sample period, there are 225 estimations for the coefficient on each explanatory variable. In the second step, we test whether the coefficient on each explanatory variable has non-zero time-series mean. First cross-sectional regressions focus on the predictive power of each of several option-implied volatility measures, CPIV , IVSKEW , AMB , COMA, POMA and RVIV . Then, various volatility measures are included in the same model in order to compare the predictive power of each measure. Such an analysis sheds light on which volatility measure is the most useful in predicting individual stock returns.

Furthermore, we test the predictive ability of different option-implied volatility measures at various investment horizons from one week to three months. Results for oneweek and two-week horizons and results for two-month and three-month horizons are similar. Therefore, we only report the results for one-week, one-month and three-month investment horizons to save space. ${ }^{14}$ Finally, we perform subperiod analysis and compare results before and after the 2008 Global Financial Crisis.

\footnotetext{
${ }^{14}$ Results for two-week and two-month investment horizons are available upon request.
} 


\subsubsection{The Full Period Analysis}

First, we examine the predictive power of each volatility measure covering the full sample period. Then, we test how each volatility measure performs when competing with others through multivariate regressions. Exhibit 4 shows results for the one-week investment horizon.

\section{[Insert Exhibit 4 here]}

Models I to VI focus on the predictive power of each option-implied volatility measure individually. Model I indicates that stocks with higher CPIV outperform those with lower CPIV in the following one-week period. Such a positive relationship between CPIV and stock returns is significant at a 1\% level. Model II investigates how IVSKEW correlates with one-week ahead stock returns. The statistically significant and negative coefficient on IVSKEW confirms a negative relationship between stock returns and IVSKEW . Model III provides evidence in favor of a marginally significant predictive ability of $A M B$. Inconsistent with our expectations, empirical results show that $A M B$ is negatively related to one-week ahead stock returns. For the one-week investment horizon, we do not find any evidence about the significant impact of COMA, POMA or RVIV on tock returns.

The remaining four models in Exhibit 4 (Models VII to X) investigate which optionimplied volatility measures have stronger predictive power when competing with other measures. Models VIII and X indicate that among six option-implied volatility measures, IVSKEW has significant predictive power. ${ }^{15}$ Furthermore, Models VII and IX indicate that both CPIV and POMA play important roles in explaining the significant predictive power of IVSKEW . That is, both at-the-money call and put options and out-of-the-money put options capture relevant information about return prediction.

\footnotetext{
${ }^{15}$ If IVSKEW and CPIV / POMA are included in the same multi-variate regression model, IVSKEW still gains significant predictive ability whereas the predictive power of CPIV / POMA disappears.
} 
The multicollinearity issue may affect the significant coefficient on $A M B$. In these three models, the relationship between $A M B$ and one-week ahead stock returns becomes stronger compared to what is shown in Model III of Exhibit 4. As discussed in subsections 2.2.3 and 2.2.6, $A M B$ measures the volatility curve asymmetries. Compared with three other measures (IVSKEW , COMA and POMA) that reflect the shape of implied volatility curve, $A M B$ is constructed using both in-the-money and out-of-the-money options. In-the-money options may not capture information as we expect due to infrequent trading activity.

Finally, over the one-week horizon, $R V I V$ has marginally significant power in predicting future stock returns when competing with other option-implied volatility measures. This is consistent with the finding of portfolio level analysis discussed in Section 3.2.

In order to examine whether the predictive power of different option-implied volatility measures persists over longer periods, we investigate how different measures perform in predicting one-month ahead stock returns. Exhibit 5 presents corresponding results.

\section{[Insert Exhibit 5 here]}

Models I and II indicate that the predictive power of CPIV or IVSKEW persists over a longer investment horizon. Model $\mathrm{V}$ of Exhibit 5 indicates that a higher POMA predicts lower one-month ahead stock return. Such a negative relationship is significant at the $5 \%$ level. Then, Models VIII to X indicate that, when competing with other option-implied volatility measures, IVSKEW has additional significant predictive power. The significant and negative slope on IVSKEW is driven by deviations from put-call parity and volatility curve asymmetry. As shown in Models VII and IX, even though both CPIV and POMA have significant slopes, the predictive power of $C P I V$ is more significant. Compared to results in Exhibit 4, RVIV loses it predictive power for the one-month horizon.

Finally, we test the predictability of different option-implied volatility measures over the three-month horizon. 


\section{[Insert Exhibit 6 here]}

As shown in Exhibit 6, regressions models focusing on each individual option-implied volatility measure (Models I to VI) further confirm the predictive power of CPIV, IVSKEW , and POMA on stock returns. In the remaining four models (Models VII to $\mathrm{X}$ ), it is obvious that the predictability of IVSKEW stems from information captured by both CPIV and POMA. Meanwhile, out-of-the-money call implied skew becomes important in return prediction, since COMA has a marginally significant and positive slope in cross-sectional regressions (Models VII and IX).

Results in Exhibits 4 to 6 imply an asymmetric effect of the volatility risk. As can be inferred from Exhibit 1, COMA reflects information on the right and middle part of the volatility curve, and IVSKEW and POMA reflect information on the left and middle part of the volatility curve. The right part of the implied volatility curve captures positive information (investors with bullish expectations choose to trade out-of-the-money call options)right part of the implied volatility curve actually captures negative information (investors choose to trade out-of-the-money put options to be protected from large negative jumps), while the left part of the implied volatility curve actually captures negative information (investors choose to trade out-of-the-money put options to be protected from large negative jumps) left part of the implied volatility curve captures positive information (investors with bullish expectations choose to trade out-of the-money call options). Results for multivariate regressions reflect that investors may treat these two kinds of information differently. For shorter investment horizons, investors are more sensitive to negative information captured by out-of-the-money put options, and such kind of information predicts future stock returns. For longer horizons, there is more uncertainty about future market conditions, and there is a higher chance that out-of-the-money call options come in-themoney at maturity. Information captured by out-of-the-money call options becomes 
increasingly important as investment horizons extend. Thus, COMA predicts stock returns over longer horizon. Even though both COMA and POMA capture the shape of the implied volatility curve, these two measures do not predict stock returns in the same way.

From results discussed in this subsection, it is inferred that, among all six option-implied volatility measures, IVSKEW has the most significant power in predicting future stock returns. ${ }^{16}$ For the one-week investment horizon, the significant effect of IVSKEW is affected by deviations from put-call parity and the left part of implied volatility curve. For one-month and three-month horizons, the predictive power of POMA becomes weaker. For longer investment horizon, like three-month, positive news is important for investors since they are more optimistic about the long-term performance of the market. Thus, COMA gains a significant coefficient in cross-sectional regressions.

\subsubsection{The Subperiod Analysis}

Our sample period is from 1996 to 2014, and it covers the financial crisis. It is interesting to examine whether information captured by different kinds of options is perceived in the same way before and after the recent financial crisis. In this subsection, firmlevel cross-sectional regressions are conducted for two sub periods: before and after September 2008. Exhibits 7 and 8 show how option-implied volatility measures perform in predicting one-week ahead stock returns before and after the crisis, respectively.

\section{[Insert Exhibits 7 \& 8 here]}

Compared to results presented in Exhibit 4, similar results can be found in Exhibits 7 and 8. That is, IVSKEW is important in predicting one-week ahead stock returns in both sub periods. The role played by CPIV or POMA seems to change during two subperiods.

\footnotetext{
${ }^{16}$ In addition to firm-level cross-sectional regressions, this study also performs pooled regressions for the sample, which involves both time-series and cross-sectional data. Results for pooled regressions confirm the importance of CPIV and IVSKEW in predicting future stock returns over various horizons from one-week to three-month. A higher CPIV predicts a higher future stock return, whereas a higher IVSKEW predicts a lower future stock return. Furthermore, controlling for time fixed effects does not affect the significance of the predictive power of $C P I V$ and IVSKEW . More detailed results are available upon requests.
} 
CPIV has predictive power before the crisis, but its predictive ability does not persist after the crisis. However, for POMA, the predictability over the one-week horizon becomes stronger after the crisis. After the crisis, investors would be more sensitive to negative shocks (i.e., crashes) captured by the left part of the put implied volatility curve. Thus, for the oneweek investment horizon, potential negative jumps captured by IVSKEW would contain relevant information about stock return prediction. No matter which sample period is investigated, the predictability of IVSKEW at the one-week horizon is stronger than any other measures used in this study.

\section{Discussion}

Results of empirical tests presented above provide useful insights about how optionimplied volatility measures perform in predicting future stock returns. From Exhibit 1, it is clear that different option-implied volatility measures capture different portions of the implied volatility curve. Thus, different volatility measures perform differently in predicting stock returns. This section discusses why some measures (especially IVSKEW and CPIV) dominate others in predicting future stock returns.

\subsection{Informed Trading}

The volatility curve asymmetry could be due to investors' trading in option markets (Bollen and Whaley, 2004). When the demand for a particular option contract is strong, due to arbitrage limits, competitive risk-averse option market makers are not able to hedge their positions perfectly and they require a premium for taking this risk. As a result, the demand for an option drives up its price. In this type of equilibrium, one would expect a positive relation between option expensiveness which can be measured by implied volatility and enduser demand. Investors with positive (negative) expectations about the future market conditions will increase their demand for call (put) options and/or reduce their demand for 
puts (calls), implying an increase in call (put) implied volatility and/or a decrease in put (call) implied volatility.

By using a VAR-bivariate-GARCH model, Bali and Hovakimian (2009) provide evidence supporting a significant volatility spillover effect where information propagates from individual equity options to individual stocks. Due to this spillover effect, optionimplied information could contain useful information about stock return prediction.

From the previous literature, if investors choose to trade in option markets first, their trading activities will generate volatility curve asymmetry. The volatility curve asymmetry captures relevant information in predicting future stock returns due to spillover effect from option markets to stock markets.

Previous literature discusses potential reasons which drive trading activities in option markets. Bali and Hovakimian (2009) claim that informed investors, who know that stock prices will change but are not sure about the direction, choose to trade in the options market. This could be due to the fact that options provide leverage for investors; investors get much higher profits from trading options than those from trading underlying stocks. Also, trading options provide insurance for undesirable changes in underlying asset prices.

Cremers and Weinbaum (2010) show that deviations from put-call parity are more likely to occur in stocks with high probability of informed trading (PIN), supporting the view that CPIV contains information about future prices of underlying stocks. Furthermore, deviations from put-call parity tend to predict returns to a greater extent in firms that face a more asymmetric information environment.

Consistently, Xing, Zhang and Zhao (2010) find that the predictive power of the implied volatility skew is driven by informed trading. That is, informed traders act in the options market and that the stock market is slow to incorporate information from the options market. 
Furthermore, information captured by the implied volatility skew is closely related to firm fundamentals, which can predict subsequent underlying asset returns.

Lin and Lu (2015) document that insider traders choose to trade in option markets first. The predictive power of option implied volatilities on stock returns becomes stronger around analyst-related events. This finding supports the fact argument that the predictability of option-implied volatilities is driven by insiders' information on upcoming analyst-related news.

Overall, option-implied information captures relevant information about future movements in underlying asset prices due to the spillover effect of informed trading from option markets to stock markets.

\subsection{Skewness Preference}

Investors' preference to-over skewness also helps explain the relationship between option-implied volatility measures and future stock returns. Bakshi, Kapadia and Madan (2003) show that a more negative risk-neutral skewness is equivalent to a steeper slope of implied volatility curve, everything else being equal. This indicates a negative relationship between IVSKEW / POMA and risk-neutral skewness and a positive relationship between $A M B$ / COMA and risk neutral skewness. The negative relationship between IVSKEW ( POMA) and future stock returns shown in previous analysis indicates a negative skewness preference. However, the negative relationship between $A M B$ and future stock returns shows conflicting findings: a positive skewness preference.

Existing literature also documents mixed results about skewness preference. Bali, Cakici and Whitelaw (2011), Bali and Murray (2013), and Conrad, Dittmar and Ghysels (2013) find a positive skewness preference, whereas Rehman and Vilkov (2012), Stilger, Kostakis and Poon (2015), and Xing, Zhang and Zhao (2010) document a negative skewness preference. 
Due to mixed findings about skewness preference in previous literature, Lazos, Coakley and Liu (2015) investigate how heterogeneous expectations affect skewness preference. Their empirical analysis shows that when investors are pessimistic (optimistic), their overconfidence produces an undervaluation (overvaluation) which explains their negative skewness preference. The overconfidence of neutral investors who exhibit either pessimism or optimism leads to overvaluation of assets, indicating a positive skewness preference. Thus, investors with heterogeneous expectations may have different preference to-over skewness.

Variables IVSKEW and POMA capture pessimistic fears. The negative relationship between IVSKEW / POMA and stock returns are consistent with the negative skewness preference of pessimistic investors. The variable $A M B$ captures neutral expectations (pessimistic expectations in the left tail and optimistic expectations in the right tail). Due to the positive relationship between $A M B$ and risk neutral skewness, a negative relationship between $A M B$ and stock returns indicates that investors are willing to accept lower returns in order to pursue higher skewness. This is consistent with the positive skewness preference of neutral investors.

\subsection{Put-Call Parity}

Next, we focus on why call-put implied volatility spreads (capturing deviation from putcall parity) predict future stock returns. Put-call parity indicates a relationship between prices of call and put options with the same expiration date and strike price.

$$
P_{t}+S_{t}-D_{t}=C_{t}+K e^{-r(T-t)}
$$

where $t$ as the current time, $T$ as the time of expiration, $S_{t}$ as the price of the underlying asset, $K$ as the strike price, $r$ as the continuous risk-free rate, and $D_{t}$ as the present value of dividends paid on the underlying asset before expiration, and $C_{t}$ and $P_{t}$ are prices of call and put options. It is expected that equation (7) holds in perfect markets. Due to the existence of 
market frictions, following Finucane (1991), the put-call parity after controlling option bidask spread could be written as:

$$
\begin{gathered}
P_{t}^{a}-C_{t}^{b}-K e^{-r(T-t)}+S_{t}-D_{t} \geq 0 \\
C_{t}^{a}-P_{t}^{b}+K-S_{t}+D_{t} \geq 0
\end{gathered}
$$

where $P_{t}^{b}, C_{t}^{b}, P_{t}^{a}$ and $C_{t}^{a}$ are the put and call bid and ask prices. Defining $\delta_{t}^{C}$ and $\delta_{t}^{P}$ as the bid-ask spreads of the call and put options,

$$
\begin{aligned}
& C_{t}^{a}=C_{t}^{b}+\delta_{t}^{C} \\
& P_{t}^{b}=P_{t}^{a}-\delta_{t}^{P}
\end{aligned}
$$

and substituting (10) and (11) into (9) yields the second condition in terms of $C_{t}^{b}$ and $P_{t}^{a}$ :

$$
C_{t}^{b}-P_{t}^{a}+K-S_{t}+D_{t}+\left(\delta_{t}^{C}+\delta_{t}^{P}\right) \geq 0
$$

Defining

$$
E_{t} \equiv C_{t}^{b}-P_{t}^{a}+K e^{-r(T-t)}-S_{t}+D_{t}
$$

and substituting into (8) and (12) yields the frictionless market bounds for the measure $E_{t}$

$$
K\left(e^{-r(T-t)}-1\right)-\delta_{t}^{C}-\delta_{t}^{P} \leq E_{t} \leq 0
$$

$E_{t}$, which may be interpreted as a measure of deviation from put-call parity, is used as the basic measure of relative put and call prices. Higher values of $E_{t}$ mean that calls are priced high relative to puts, and lower values imply relatively high put prices.

By calculating $E_{t}$ for each individual asset, we are able to distinguish stocks with no violation of equation (14) and we would expect that put-call parity holds by distinction definition for these stocks. For these stocks, we test whether CPIV captures important information about future stock returns. For stocks with no deviation from put-call parity 
under the control of option bid-ask spread from equation (14), results show that CPIV is still significantly and positively related to future stock returns. ${ }^{17}$

The upper and lower bounds used in equation (14) fail to reflect other frictions, such as constraints on short sale. That is, for stocks with no deviation from put-call parity after controlling for option bid-ask spread, CPIV still has significant predictive power. This may indicate that the market is not frictionless and option-implied volatility measures capture other relevant information, such as constraints on short sale, which are discussed in the next subsection.

\subsection{Short Sale Constraints}

In stock markets, following a buy-and-hold strategy generates profits if stock price increases. On the other hand, to avoid potential loss due to a decrease in a stock price in the future, pessimistic investors holding the stock choose to sell it. Pessimistic investors who do not hold the stock are able to make profits only by short selling the stock.

In order to short sell a stock, borrowers have to find lenders who hold the stock and are willing to lend the stock to others. After posting a collateral as required, borrowers can borrow the stock from lenders and sell it at the market price. If the stock price decreases, borrowers will repurchase the same shares back but at a lower price. Then, borrowers return the stock back to lenders and get the collateral back together with the rebate rate. ${ }^{18}$ During such a process, lenders will charge borrowers a fee (i.e., the repo rate for individual stocks).

\footnotetext{
${ }^{17}$ The results for portfolio level analysis on CPIV among stocks with no deviation from put-call parity as shown in equation (14) show that the average return on the equally-weighted " 5 - 1 " long-short portfolio constructed on CPIV is $0.88 \%$ per month (with a p-value close to 0 ), and the average return on the valueweighted " $5-1$ " long-short portfolio is $0.71 \%$ per month (with a p-value of 0.0012 ). More details are available upon request.

${ }^{18}$ In order to short sell an asset, borrowers have to put up a collateral to lenders. After borrowers return the asset back to lenders, lenders need to give the collateral back and also pay rebate rates (e.g., the portion of interest or dividends of shares earned from the collateral) to borrowers. Thus, the rebate rate is a proxy for the difficulty of short selling from the stock lending market. If short selling is difficult, the rebate rate will be lower and can even become negative.
} 
Thus, from short sale, profits for borrowers are always less than the magnitude of decrease in stock price.

In stock markets, constraints on short sale exist (e.g. difficulty in borrowing shares, fee paid to the lender, fee paid to the broker, etc.). Studies claim that short sale constraints predict future stock returns (e.g., Figlewski, 1981; Ofek, Richardson and Whitelaw, 2004; Cohen, Diether and Malloy, 2007).

Under the condition of no arbitrage, the put-call parity holds if there is no friction in the market. By rearranging Equation (7), we can get:

$$
S_{t}=C_{t}-P_{t}+K e^{-r(T-t)}+D_{t}
$$

If the stock market price is different from the price implied in Equation (15), stock market price and implied price will converge to the same level due to investors' arbitrage activities. However, due to the existence of constraints on short sale and the repo rate, when stock market prices are higher than implied prices, there does not exist an arbitrage which leads to the convergence of two values (Lamont and Thaler, 2003; Ofek and Richardson, 2003; and Ofek, Richardson and Whitelaw, 2004).

In the presence of short sale constraints, through trading call and put options, option markets provide investors the chance to short stocks that they may not be able to borrow and sell in stock markets (Figlewski and Webb, 1993), and put options become relatively expensive compared with their corresponding calls. Figlewski and Webb (1993) document that the difference between put and call implied volatilities is closely correlated with short interest, a proxy for constraints on short sale. ${ }^{19}$ Ofek, Richardson and Whitelaw (2004) provide supportive evidence that, for stocks that are difficult or expensive to short, a deviation from put-call parity is more likely to be observed. Thus, deviation from put-call

\footnotetext{
${ }^{19}$ A stock's short interest refers to the total number of shares that have been sold short and not yet covered (repurchased) as of a point in time.
} 
parity may reflect difficulty in short selling stocks and may contain useful information about stock return prediction.

By using the rebate rate as a proxy, Cremers and Weinbaum (2010) fail to find evidence that predictability of option-implied information is driven by stocks that are hard to short. However, such a finding could be affected by the data limitation, since they use private data only covering two-year period from October 2003 to December 2005.

Thus, due to the constraints on short-sale, frictions exist for short sellers due to the repo rate paid by borrowers to lenders. This further indicates that put-call parity may not hold in presence of such frictions. The call-put implied volatility spread, CPIV, may capture the unobserved repo rate of individual stocks and reflect how difficult it is to short sell the underlying stock. So, constraints on short sale could be a potential reason for the predictive ability of option-implied volatility measures. ${ }^{20}$

\subsection{Delta-Hedge Trading Strategy}

Doran and Krieger (2010) propose that the predictive power of option-implied volatility measures on stock returns could be due to trading activities of delta-hedge traders. For example, if CPIV increases, in order to be delta-neutral, option traders need to purchase the underlying stock to hedge the increase in delta. The purchase of the underlying stock will drive up future stock prices and further lead to a positive future stock return.

Thus, in addition to skewness preference and constraints on short sale, delta rebalancing is another potential reason for the predictability of option-implied volatility measures on stock returns.

\footnotetext{
${ }^{20}$ As claimed by Adrian, Begalle, Copeland and Martin (2012), repo rates are hard to collect. Thus, repo rates have not been used in this study.
} 


\section{Conclusion}

This study focuses on the relationship between option-implied volatility measures and future stock returns and results can be summarized as follows. First, a portfolio level analysis implies a positive relationship between $C P I V$ and one-month ahead portfolio returns and a negative relationship between IVSKEW and $R V I V$ and future one-month portfolio returns.

Firm-level cross-sectional regressions indicate that, over different investment horizons (from one-week to three-month), IVSKEW has the most important predictive information. Both deviations from put-call parity and put implied volatility curve capture useful information in return prediction over various horizons. However, the predictive power of the put implied volatility curve becomes weaker for one-month and three-month horizons.

In addition, we confirm the asymmetric effect of volatility risk. Out-of-the-money call and put options capture fundamentally different information about future stock returns. Our results imply that investors care about and overweigh negative future return shocks, especially over short horizons. Additionally, over longer horizons (three-month), investors take positive expectations into consideration as well.

Finally, the subsample analysis confirms that the strong predictive ability of IVSKEW over one-week horizon persists before and after the recent crisis. The driver of the effect of IVSKEW on one-week ahead stock returns changes during the full sample period. Before the financial crisis, the main driver is a deviation from put-call parity. However, after the crisis, POMA is more important in predicting one-week ahead stock returns, suggesting that investors are more sensitive to negative shocks captured by out-of-the-money put options. 


\section{References}

Adrian, T., Begalle, B., Copeland, A., and Martin, A., 2012, Repo and Securities Lending, NBER Working Paper.

An, B. J., Ang, A., Bali, T. G., and Cakici, N., 2014, The Joint Cross-Section of Stocks and Options, The Journal of Finance, Vol. 69, pp. 2279-2337.

Arisoy, Y. E., 2014, Aggregate Volatility and Market Jump Risk: An Option-Based Explanation to Size and Value Premia, The Journal of Future Markets, Vol. 34, pp. 34-55.

Bakshi, G., Kapadia, N., and Madan, D., 2003, Stock Return Characteristics, Skew Laws, and the Differential Pricing of Individual Equity Options, Review of Financial Studies, Vol. 16, pp. 101-143.

Bali, T. G., and Hovakimian, A., 2009, Volatility Spreads and Expected Stock Returns, Management Science, Vol. 55, pp. 1797-1812.

Bali, T. G., and Murray, S., 2013, Does Risk-Neutral Skewness Predict the Cross-Section of Equity Option Portfolio Returns, Journal of Financial and Quantitative Analysis, Vol. 48, pp. $1145-1171$.

Bali, T. G., Cakici, N., and Whitelaw, R. F., 2011, Maxing Out: Stocks as Lotteries and the Cross-Section of Expected Returns, Journal of Financial Economics, Vol. 99, pp. 427-446.

Baltussen, G., Grient, B. V. D., Groot, W. D., Hennink, E., and Zhou, W., 2012, Exploiting Option Information in the Equity Market, The Financial Analysts Journal, Vol. 68, pp. 56-72.

Banz, R. W., 1981, The Relationship between Return and Market Value of Common Stocks, The Journal of Financial Economics, Vol. 9, pp. 3-18.

Bates, D. S., 2000, Post-'87 Crash Fears in the S\&P 500 Futures Option Market, The Journal of Econometrics, Vol. 94, pp. 181-238.

Bates, D. S., 2003, Empirical Option Pricing: A Retrospection, The Journal of Econometrics, Vol. 116, pp. 387-404.

Bollen, N. P. B., and Whaley, R. E., 2004, Does Net Buying Pressure Affect the Shape of Implied Volatility Functions? The Journal of Finance, Vol. 59, pp. 711-753.

Christensen, B. J., and Prabhala, N. R., 1998, The Relation between Implied and Realized Volatility, The Journal of Financial Economics, Vol. 50, pp. 125-150.

Cohen, L., Diether, K., and Malloy, C., 2007, Supply and Demand Shifts in the Shorting Market, The Journal of Finance, Vol. 62, pp. 2061-2096.

Conrad, J., S., Dittmar, R. F., and Ghysel, E., 2009, Ex Ante Skewness and Expected Stock Returns. Journal of Finance, Vol. 68, pp. 85-124. 
Cremers, M., and Weinbaum, D., 2010, Deviations from Put-Call Parity and Stock Returns Predictability, The Journal of Financial and Quantitative Analysis, Vol. 45, pp. 335-367.

Doran, J. S., and Krieger, K., 2010, Implications for Asset Returns in the Implied Volatility Skew, The Financial Analysts Journal, Vol. 66, pp. 65-76.

Doran, J. S., Peterson, D. R., and Tarrant, B. C., 2007, Is There Information in the Volatility Skew? The Journal of Futures Markets, Vol. 27, pp. 921-959.

Fama, E. F., and French, K. R., 1992, The Cross-Section of Expected Stock Returns, The Journal of Finance, Vol. 47, pp. 427-465.

Figlewski, S., 1981, The Informational Effects of Restrictions on Short Sales: Some Empirical Evidence, The Journal of Financial and Quantitative Analysis, Vol. 16, pp. 463476.

Figlewski, S., and Webb, G., 1993, Options, Short Sales, and Market Completeness, The Journal of Finance, Vol. 48, pp. 761-777.

Finucane, T. J., 1991, Put-Call Parity and Expected Returns, Journal of Financial and Quantitative Analysis, Vol. 26, pp. 445-457.

Gârleanu, N., Pedersen, L. H., and Poteshman A., 2009, Demand-Based Option Pricing, The Review of Financial Studies, Vol. 22, pp. 4259-4299.

Gemmill, G., 1996, Did Option Traders Anticipate the Crash? Evidence from Volatility Smiles in the UK with US Comparisons, The Journal of Futures Markets, Vol. 16, pp. 881897.

Hull, J.C., 2012, Options, Futures, and Other Derivatives, $8^{\text {th }}$ Edition, Pearson.

Jegadeesh, N., and Titman, S., 1993, Returns to Buying Winners and Selling Losers: Implications for Stock Market Efficiency, The Journal of Finance, Vol. 48, pp. 65-91.

Kang, B. J., Kim, T. S., and Yoon, S. J., 2010, Information Content of Volatility Spreads, The Journal of Futures Markets, Vol. 30, pp. 533-558.

Lamont, O., and Thaler, R., 2003, Can the Market Add and Subtract? Mispricing in Tech Stock Carve-Outs, The Journal of Political Economy, Vol. 111, pp. 227-268.

Lazos, A., Coakley, J., and Liu, X., 2015, Investor Heterogeneity, Sentiment, and Skewness Preference in Options, Working Paper.

Lin, T., and Lu, X., 2015, Why Do Options Prices Predict Stock Returns? Evidence from Analyst Tipping. The Journal of Banking and Finance, Vol. 52, pp. 17-28.

Muzzioli, S., 2011, The Skew Pattern of Implied Volatility in the DAX Index Options Market, Frontiers in Finance and Economics, Vol. 8, pp. 43-68.

Ofek, E., and Richardson, M., 2003, DotCom Mania: The Rise and Fall of Internet Stock Prices, The Journal of Finance, Vol. 58, pp. 1113-1137. 
Ofek, E., Richardson, M., and Whitelaw, R., 2004, Limited Arbitrage and Short Sales Restrictions: Evidence from the Options Markets, The Journal of Financial Economics, Vol. 74, pp. 305-342.

Pan, J., and Poteshman, A. M., 2006, The Information in Option Volume for Future Stock Prices, The Review of Financial Studies, Vol. 19, pp. 871-908.

Poon, S. H., and Granger, C., 2005, Practical Issues in Forecasting Volatility, The Financial Analysts Journal, Vol. 61, pp. 45-56.

Rehman, Z., and Vilkov, G., 2012, Risk-Neutral Skewness: Return Predictability and Its Sources, Working Paper.

Stilger, P. S., Kostakis, A., and Poon, S., 2016, What Does Risk-Neutral Skewness Tell Us About Future Stock Returns? Management Science, Forthcoming.

Szakmary, A., Ors, E., Kim, J. K., and Davidson, W. N., 2003, The Predictive Power of Implied Volatility: Evidence from 35 Futures Markets, The Journal of Banking and Finance, Vol. 27, pp. 2151-2175.

Taylor, S. J., Yadav, P. K., Zhang, Y., 2010, The Information Content of Implied Volatilities and Model-Free Volatility Expectations: Evidence from Options Written on Individual Stocks, The Journal of Banking and Finance, Vol. 34, pp. 871-881.

Xing, Y., Zhang, X., and Zhao, R., 2010, What Does the Individual Option Volatility Smirk Tell Us about Future Equity Returns? The Journal of Financial and Quantitative Analysis, Vol. 45, pp. 641-662.

Yu, W. W., Lui, E. C. K., and Wang, J. W., 2010, The Predictive Power of the Implied Volatility of Options Traded OTC and on Exchanges, The Journal of Banking and Finance, Vol. 34, pp. 1-11. 
Exhibit 1: Volatility Curve Asymmetry and Implied Volatility Measures

Notes: This exhibit plots implied volatility extracted from each call and put options on Adobe Systems Inc on December 29, 2000. To get this exhibit, only options with expiration date of February 17, 2001 are retained. The closing price for Adobe Systems Inc on December 29, 2000 is 58.1875.

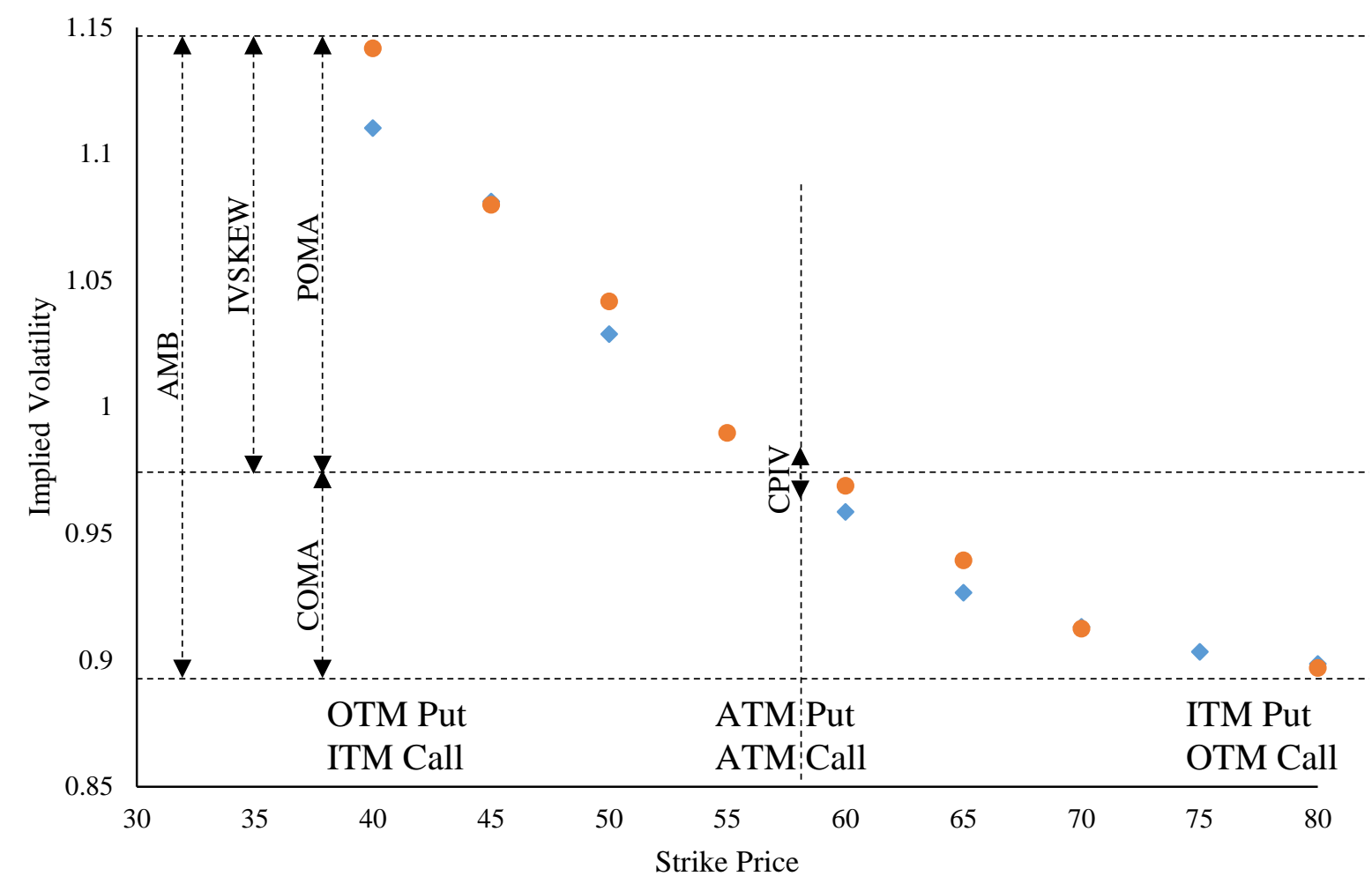

$\diamond$ Call Implied Volatility $\quad$ Put Implied Volatility 
Exhibit 2: Summary Statistics

Notes: Descriptive statistics presented in Exhibit 2 are calculated based on option-implied volatility measures and firm-specific variables at the end of each calendar month from January 1996 to October 2014.

\begin{tabular}{lcccccccccc}
\hline \multicolumn{10}{c}{ Panel A: Full Sample } \\
\hline & Mean & Std & Min & $5^{\text {th }}$ Pct & $25^{\text {th }}$ Pct & Median & $75^{\text {th }}$ Pct & $95^{\text {th }}$ Pct & Max & Sample Size \\
CPIV & -0.0072 & 0.0479 & -2.4244 & -0.0664 & -0.0187 & -0.0046 & 0.0085 & 0.0459 & 1.3637 & 230884 \\
IVSKEW & 0.0631 & 0.0655 & -1.0576 & -0.0047 & 0.0319 & 0.0534 & 0.0809 & 0.1594 & 2.0332 & 121205 \\
AMB & -0.0810 & 0.0934 & -1.0599 & -0.2385 & -0.1262 & -0.0727 & -0.0281 & 0.0466 & 0.6575 & 66104 \\
COMA & -0.0199 & 0.0434 & -1.3960 & -0.0742 & -0.0366 & -0.0196 & -0.0034 & 0.0317 & 2.5235 & 109321 \\
POMA & 0.0526 & 0.0482 & -0.8965 & -0.0033 & 0.0271 & 0.0463 & 0.0693 & 0.1287 & 2.0444 & 116557 \\
RVIV & -0.0188 & 0.1848 & -3.2866 & -0.2291 & -0.1021 & -0.0390 & 0.0349 & 0.2598 & 21.0411 & 285144 \\
\hline
\end{tabular}

\begin{tabular}{|c|c|c|c|c|c|c|c|c|c|}
\hline \multicolumn{10}{|c|}{ Panel B: Intersection Sample (Sample Size $=62562$ ) } \\
\hline IVSKEW & 0.0676 & 0.0671 & -0.5534 & -0.0046 & 0.0328 & 0.0561 & 0.0877 & 0.1758 & 1.5713 \\
\hline COMA & -0.0245 & 0.0341 & -0.5434 & -0.0771 & -0.0393 & -0.0225 & -0.0074 & 0.0212 & 0.6904 \\
\hline POMA & 0.0568 & 0.0506 & -0.2255 & -0.0027 & 0.0282 & 0.0488 & 0.0747 & 0.1414 & 1.0365 \\
\hline$R V I V$ & -0.0031 & 0.2265 & -2.0835 & -0.2477 & -0.1063 & -0.0323 & 0.0652 & 0.3399 & 9.2399 \\
\hline
\end{tabular}


(Continued)

\begin{tabular}{|c|c|c|c|c|c|c|}
\hline \multicolumn{7}{|c|}{ Panel C: Correlation Table for the Intersection Sample } \\
\hline & CPIV & IVSKEW & $A M B$ & COMA & POMA & $R V I V$ \\
\hline IVSKEW & -0.6580 & & & & & \\
\hline$A M B$ & -0.3010 & -0.3107 & & & & \\
\hline POMA & 0.0295 & 0.7333 & -0.6842 & -0.5679 & & \\
\hline$R V I V$ & 0.0031 & 0.0701 & -0.0275 & -0.0220 & 0.0958 & \\
\hline $\ln ($ size $)$ & 0.1151 & 0.0202 & -0.1409 & -0.0651 & 0.1307 & 0.0525 \\
\hline Stock Volume & 0.0212 & 0.1027 & -0.1180 & -0.1016 & 0.1554 & 0.1023 \\
\hline Market Beta & 0.0047 & 0.0451 & -0.0576 & -0.0716 & 0.0641 & 0.2506 \\
\hline Bid - Ask Spread & -0.0231 & -0.0839 & 0.1720 & 0.1335 & -0.1322 & 0.0419 \\
\hline Option Volume & 0.0058 & 0.0722 & -0.0660 & -0.0146 & 0.1011 & 0.0430 \\
\hline
\end{tabular}


Exhibit 3: Portfolio Level Analysis on Option-Implied Volatility Measures

Notes: Quintile portfolios are constructed every month by sorting stocks on each option-implied volatility measure at the end of the previous month. Call-put implied volatility spread ( CPIV) is the difference between the average implied volatility of at-the-money calls and-minus the average implied volatility of at-the-money puts. Implied volatility skew ( IVSKEW ) is dhe difference betweenthe average implied volatility of out-of-themoney puts and-minus the average implied volatility of at-the-money calls. "Above-minus-below" ( $A M B)$ is the difference between the average implied volatility of options whose strike prices are above the current underlying price and-minus the mean-average implied volatility of options whose strike prices are below the current underlying price. "Out-minus-at" of calls (COMA) is the difference between -the average implied volatility of out-of-the-money calls and minus the average implied volatility of at-the-money calls. "Out-minusat" of puts (POMA) is the difference between-the average implied volatility of out-of-the-money puts and minus the average implied volatility of at-the-money puts. Realized-implied volatility spread ( $R V I V)$ is the difference between-the realized volatility (i.e. the annualized standard deviation of daily returns over the previous month) and-minus the average of at-the-money call and put implied volatilities. Quintile 1 (5) denotes the portfolio of stocks with the lowest (highest) option-implied volatility measure. The Jensen's alphas are reported in rows labeled "Alpha". The column " $5-1$ " refers to the arbitrage portfolio with a long position in portfolio 5 and a short position in portfolio 1. The row "Return" documents data about raw returns on portfolios, and the row “Alpha” shows data about Jensen’s alpha with respect to Fama-French three factor model. P-values reported in Exhibit 3 are calculated using Newey-West method to control for serial correlation. Hereafter, *, **, and $* * *$ denote for significance at $10 \%, 5 \%$ and $1 \%$ level, respectively.

\begin{tabular}{|c|c|c|c|c|c|c|c|c|}
\hline \multicolumn{9}{|c|}{ Panel A: Equally-Weighted Portfolios } \\
\hline & & 1 & 2 & 3 & 4 & 5 & $5-1$ & p-value \\
\hline \multirow[t]{2}{*}{$C P I V$} & Return & 0.0042 & 0.0078 & 0.0096 & 0.0110 & 0.0154 & $0.0112 * * *$ & 0.0000 \\
\hline & Alpha & -0.0068 & -0.0021 & 0.0000 & 0.0014 & 0.0048 & $0.0116^{* * *}$ & 0.0000 \\
\hline \multirow[t]{2}{*}{ IVSKEW } & Return & 0.0110 & 0.0094 & 0.0083 & 0.0064 & 0.0024 & $-0.0086 * * *$ & 0.0000 \\
\hline & Alpha & 0.0011 & -0.0004 & -0.0015 & -0.0037 & -0.0089 & $-0.0099 * * *$ & 0.0000 \\
\hline \multirow[t]{2}{*}{$A M B$} & Return & 0.0082 & 0.0105 & 0.0081 & 0.0079 & 0.0042 & -0.0040 & 0.1245 \\
\hline & Alpha & -0.0025 & -0.0004 & -0.0025 & -0.0027 & -0.0069 & $-0.0044^{*}$ & 0.0666 \\
\hline \multirow[t]{2}{*}{ COMA } & Return & 0.0083 & 0.0104 & 0.0109 & 0.0092 & 0.0081 & -0.0003 & 0.8956 \\
\hline & Alpha & -0.0032 & 0.0000 & 0.0005 & -0.0012 & -0.0027 & 0.0006 & 0.7764 \\
\hline \multirow[t]{2}{*}{ POMA } & Return & 0.0061 & 0.0092 & 0.0086 & 0.0099 & 0.0061 & 0.0001 & 0.9784 \\
\hline & Alpha & -0.0042 & -0.0005 & -0.0013 & -0.0002 & -0.0048 & -0.0006 & 0.7300 \\
\hline \multirow[t]{2}{*}{$R V I V$} & Return & 0.0124 & 0.0107 & 0.0090 & 0.0090 & 0.0075 & $-0.0048 * * *$ & 0.0039 \\
\hline & Alpha & 0.0020 & 0.0010 & -0.0007 & -0.0010 & -0.0037 & $-0.0057 * * *$ & 0.0007 \\
\hline \multicolumn{9}{|c|}{ Panel B: Value-Weighted Portfolios } \\
\hline & & 1 & 2 & 3 & 4 & 5 & $5-1$ & p-value \\
\hline \multirow[t]{2}{*}{ CPIV } & Return & 0.0037 & 0.0063 & 0.0093 & 0.0098 & 0.0134 & $0.0097^{* * *}$ & 0.0002 \\
\hline & Alpha & -0.0057 & -0.0017 & 0.0018 & 0.0023 & 0.0054 & $0.0110^{* * *}$ & 0.0001 \\
\hline \multirow[t]{2}{*}{ IVSKEW } & Return & 0.0125 & 0.0113 & 0.0088 & 0.0066 & 0.0060 & $-0.0064 * *$ & 0.0133 \\
\hline & Alpha & 0.0048 & 0.0038 & 0.0016 & -0.0010 & -0.0033 & $-0.0082 * * *$ & 0.0008 \\
\hline \multirow[t]{2}{*}{$A M B$} & Return & 0.0087 & 0.0122 & 0.0071 & 0.0130 & 0.0038 & -0.0048 & 0.2925 \\
\hline & Alpha & 0.0001 & 0.0037 & -0.0013 & 0.0045 & -0.0055 & -0.0056 & 0.1753 \\
\hline \multirow[t]{2}{*}{ COMA } & Return & 0.0086 & 0.0115 & 0.0102 & 0.0086 & 0.0056 & -0.0030 & 0.4058 \\
\hline & Alpha & -0.0012 & 0.0030 & 0.0020 & 0.0004 & -0.0030 & -0.0019 & 0.5934 \\
\hline \multirow[t]{2}{*}{ POMA } & Return & 0.0084 & 0.0094 & 0.0083 & 0.0099 & 0.0085 & 0.0001 & 0.9802 \\
\hline & Alpha & 0.0005 & 0.0016 & 0.0007 & 0.0022 & 0.0000 & -0.0005 & 0.8382 \\
\hline \multirow[t]{2}{*}{$R V I V$} & Return & 0.0121 & 0.0110 & 0.0089 & 0.0070 & 0.0062 & $-0.0059 * *$ & 0.0138 \\
\hline & Alpha & 0.0034 & 0.0034 & 0.0016 & -0.0007 & -0.0030 & $-0.0064 * * *$ & 0.0039 \\
\hline
\end{tabular}


Exhibit 4: Firm-Level Cross-Sectional Regression Results Over One-Week

Notes: Exhibit 4 presents the firm-level cross-sectional regression results for the intersection sample during the full sample period. The dependent variables are one-week returns on individual stocks after factor construction at the end of each calendar month. P-values are calculated using Newey-West method.

\begin{tabular}{|c|c|c|c|c|c|c|c|c|c|c|}
\hline & I & II & III & IV & $\mathrm{V}$ & VI & VII & VIII & IX & $\mathrm{X}$ \\
\hline Intercept & 0.0049 & 0.0042 & 0.0048 & 0.0041 & 0.0042 & 0.0016 & 0.0031 & 0.0027 & 0.0032 & 0.0028 \\
\hline P-value & 0.6350 & 0.6850 & 0.6471 & 0.6947 & 0.6838 & 0.8735 & 0.7555 & 0.7852 & 0.7458 & 0.7762 \\
\hline CPIV & $0.0705^{* * *}$ & & & & & & $0.0625^{* * *}$ & & $0.0736 * * *$ & \\
\hline P-value & 0.0000 & & & & & & 0.0002 & & 0.0000 & \\
\hline IVSKEW & & $-0.0418 * * *$ & & & & & & $-0.0546 * * *$ & & $-0.0459 * * *$ \\
\hline P-value & & 0.0000 & & & & & & 0.0000 & & 0.0000 \\
\hline$A M B$ & & & $-0.0147 * *$ & & & & $-0.0252 * *$ & $-0.0296 * * *$ & & \\
\hline P-value & & & 0.0281 & & & & 0.0116 & 0.0003 & & \\
\hline СОМА & & & & -0.0158 & & & 0.0218 & 0.0295 & -0.0013 & -0.0122 \\
\hline P-value & & & & 0.4207 & & & 0.3509 & 0.1908 & 0.9538 & 0.5431 \\
\hline POMA & & & & & -0.0179 & & $-0.0532 * * *$ & & $-0.0330 * * *$ & \\
\hline $\mathrm{P}$-value & & & & & 0.1449 & & 0.0002 & & 0.0057 & \\
\hline$R V I V$ & & & & & & -0.0052 & $-0.0067 * *$ & $-0.0065 * *$ & $-0.0067 * *$ & $-0.0063 * *$ \\
\hline $\mathrm{P}$-value & & & & & & 0.1141 & 0.0413 & 0.0448 & 0.0395 & 0.0509 \\
\hline Size & 0.0001 & 0.0003 & 0.0000 & 0.0001 & 0.0002 & 0.0003 & 0.0002 & 0.0002 & 0.0002 & 0.0003 \\
\hline P-value & 0.8164 & 0.6452 & 0.9538 & 0.8410 & 0.7662 & 0.6583 & 0.7254 & 0.7090 & 0.6838 & 0.6418 \\
\hline B/M Ratio & -0.0037 & -0.0034 & -0.0032 & -0.0032 & -0.0031 & -0.0032 & -0.0034 & -0.0033 & -0.0034 & -0.0032 \\
\hline P-value & 0.1154 & 0.1378 & 0.1672 & 0.1753 & 0.1853 & 0.1633 & 0.1700 & 0.1723 & 0.1689 & 0.1807 \\
\hline Pre 1M Return & -0.0015 & -0.0014 & -0.0018 & -0.0016 & -0.0012 & -0.0017 & 0.0001 & -0.0004 & 0.0004 & 0.0000 \\
\hline P-value & 0.7366 & 0.7426 & 0.6889 & 0.7071 & 0.7812 & 0.6898 & 0.9817 & 0.9314 & 0.9181 & 0.9907 \\
\hline Stock Volume & -0.0005 & -0.0005 & 0.0003 & 0.0001 & 0.0000 & 0.0006 & 0.0006 & 0.0008 & 0.0006 & 0.0007 \\
\hline P-value & 0.6457 & 0.6271 & 0.8167 & 0.9084 & 0.9916 & 0.5323 & 0.5375 & 0.4605 & 0.5985 & 0.5206 \\
\hline Market Beta & -0.0004 & -0.0003 & -0.0004 & -0.0005 & -0.0003 & 0.0001 & 0.0000 & -0.0001 & -0.0001 & -0.0001 \\
\hline P-value & 0.7411 & 0.8135 & 0.7027 & 0.6429 & 0.8074 & 0.9141 & 0.9783 & 0.9634 & 0.9675 & 0.9634 \\
\hline Bid-ask Spread & $-0.0158 *$ & -0.0146 & $-0.0200 * *$ & $-0.0202 * *$ & $-0.0202 * *$ & $-0.0206 * *$ & $-0.0147 *$ & -0.0131 & $-0.0147 *$ & -0.0140 \\
\hline P-value & 0.0784 & 0.1104 & 0.0133 & 0.0157 & 0.0138 & 0.0126 & 0.0906 & 0.1359 & 0.0979 & 0.1185 \\
\hline Option Volume & -0.0006 & 0.0000 & -0.0029 & -0.0025 & -0.0022 & -0.0039 & -0.0033 & -0.0032 & -0.0032 & -0.0028 \\
\hline P-value & 0.8352 & 0.9924 & 0.3727 & 0.3990 & 0.4582 & 0.1951 & 0.2252 & 0.2688 & 0.2327 & 0.3131 \\
\hline
\end{tabular}


Exhibit 5: Firm-Level Cross-Sectional Regression Results Over One-Month

Notes: Exhibit 5 presents the firm-level cross-sectional regression results for the intersection sample during the full sample period. The dependent variables are one-month returns on individual stocks after factor construction at the end of each calendar month. P-values are calculated using Newey-West method.

\begin{tabular}{|c|c|c|c|c|c|c|c|c|c|c|}
\hline & I & II & III & IV & $\mathrm{V}$ & VI & VII & VIII & IX & $\mathrm{X}$ \\
\hline Intercept & 0.0211 & 0.0190 & 0.0206 & 0.0189 & 0.0188 & 0.0186 & 0.0194 & 0.0183 & 0.0179 & 0.0175 \\
\hline P-value & 0.2412 & 0.2987 & 0.2570 & 0.3031 & 0.3096 & 0.2991 & 0.2836 & 0.3037 & 0.3210 & 0.3252 \\
\hline CPIV & $0.1062 * * *$ & & & & & & $0.1148 * * *$ & & $0.1151^{* * *}$ & \\
\hline P-value & 0.0005 & & & & & & 0.0002 & & 0.0000 & \\
\hline IVSKEW & & $-0.0795 * * *$ & & & & & & $-0.0897 * * *$ & & $-0.0848 * * *$ \\
\hline P-value & & 0.0000 & & & & & & 0.0000 & & 0.0000 \\
\hline$A M B$ & & & -0.0005 & & & & -0.0094 & $-0.0233 *$ & & \\
\hline P-value & & & 0.9696 & & & & 0.6059 & 0.0815 & & \\
\hline СОМА & & & & 0.0055 & & & 0.0232 & 0.0248 & 0.0163 & -0.0083 \\
\hline P-value & & & & 0.8958 & & & 0.6207 & 0.5967 & 0.6939 & 0.8349 \\
\hline POMA & & & & & $-0.0540 * *$ & & $-0.0596 *$ & & $-0.0572 * *$ & \\
\hline $\mathrm{P}$-value & & & & & 0.0378 & & 0.0574 & & 0.0200 & \\
\hline$R V I V$ & & & & & & 0.0040 & 0.0007 & 0.0007 & 0.0001 & 0.0005 \\
\hline P-value & & & & & & 0.5237 & 0.9099 & 0.9113 & 0.9826 & 0.9349 \\
\hline Size & -0.0003 & 0.0001 & -0.0003 & -0.0001 & 0.0000 & -0.0001 & 0.0000 & 0.0000 & 0.0000 & 0.0001 \\
\hline P-value & 0.7944 & 0.9566 & 0.7899 & 0.8967 & 0.9765 & 0.8837 & 0.9634 & 0.9786 & 0.9668 & 0.9151 \\
\hline B/M Ratio & $-0.0165 * * *$ & $-0.0158 * * *$ & $-0.0159 * * *$ & $-0.0155 * * *$ & $-0.0154 * * *$ & $-0.0160 * * *$ & $-0.0157 * * *$ & $-0.0155^{* * *}$ & $-0.0153 * * *$ & $-0.0153 * * *$ \\
\hline P-value & 0.0034 & 0.0053 & 0.0047 & 0.0058 & 0.0057 & 0.0043 & 0.0053 & 0.0066 & 0.0062 & 0.0067 \\
\hline Pre 1M Return & 0.0000 & 0.0000 & -0.0006 & -0.0009 & -0.0003 & 0.0001 & 0.0027 & 0.0013 & 0.0022 & 0.0019 \\
\hline P-value & 0.9999 & 0.9988 & 0.9415 & 0.9112 & 0.9744 & 0.9872 & 0.7538 & 0.8773 & 0.8035 & 0.8294 \\
\hline Stock Volume & -0.0034 & -0.0035 & -0.0027 & -0.0032 & -0.0030 & -0.0026 & $-0.0035 *$ & $-0.0032 *$ & $-0.0033 *$ & -0.0030 \\
\hline P-value & 0.1126 & 0.1014 & 0.2104 & 0.1350 & 0.1650 & 0.2366 & 0.0680 & 0.0976 & 0.0962 & 0.1306 \\
\hline Market Beta & 0.0003 & 0.0008 & 0.0006 & 0.0005 & 0.0009 & 0.0010 & 0.0011 & 0.0011 & 0.0012 & 0.0012 \\
\hline P-value & 0.8864 & 0.6793 & 0.7657 & 0.8117 & 0.6408 & 0.6296 & 0.6060 & 0.5962 & 0.5587 & 0.5599 \\
\hline Bid-ask Spread & -0.0150 & -0.0163 & $-0.0295 *$ & $-0.0298 *$ & $-0.0314^{* *}$ & $-0.0287 *$ & -0.0140 & -0.0130 & -0.0132 & -0.0139 \\
\hline P-value & 0.3443 & 0.2751 & 0.0566 & 0.0592 & 0.0489 & 0.0549 & 0.3718 & 0.3739 & 0.3894 & 0.3442 \\
\hline Option Volume & 0.0046 & 0.0057 & 0.0018 & 0.0031 & 0.0038 & 0.0011 & 0.0042 & 0.0035 & 0.0033 & 0.0034 \\
\hline P-value & 0.5283 & 0.4125 & 0.8016 & 0.6692 & 0.5923 & 0.8760 & 0.5240 & 0.5963 & 0.6116 & 0.6039 \\
\hline
\end{tabular}


Exhibit 6: Firm-Level Cross-Sectional Regression Results Over Three-Month

Notes: Exhibit 6 presents the firm-level cross-sectional regression results for the intersection sample during the full sample period. The dependent variables are one-quarter returns on individual stocks after factor construction at the end of each calendar month. P-values are calculated using Newey-West method.

\begin{tabular}{|c|c|c|c|c|c|c|c|c|c|c|}
\hline & I & II & III & IV & $\mathrm{V}$ & VI & VII & VIII & IX & $X$ \\
\hline Intercept & 0.0378 & 0.0385 & 0.0380 & 0.0370 & 0.0374 & 0.0379 & 0.0375 & 0.0373 & 0.0369 & 0.0372 \\
\hline P-value & 0.4606 & 0.4553 & 0.4647 & 0.4762 & 0.4769 & 0.4640 & 0.4667 & 0.4663 & 0.4747 & 0.4669 \\
\hline CPIV & $0.1301^{* *}$ & & & & & & $0.1719 * * *$ & & $0.1681^{* * *}$ & \\
\hline P-value & 0.0146 & & & & & & 0.0009 & & 0.0011 & \\
\hline IVSKEW & & $-0.1541^{* * *}$ & & & & & & $-0.1565 * * *$ & & $-0.1590 * * *$ \\
\hline P-value & & 0.0001 & & & & & & 0.0000 & & 0.0000 \\
\hline$A M B$ & & & 0.0085 & & & & -0.0249 & -0.0312 & & \\
\hline P-value & & & 0.7334 & & & & 0.3785 & 0.1944 & & \\
\hline СОМА & & & & 0.1060 & & & $0.1459 *$ & 0.1298 & $0.1281^{*}$ & 0.0903 \\
\hline P-value & & & & 0.1555 & & & 0.0754 & 0.1106 & 0.0946 & 0.2186 \\
\hline POMA & & & & & $-0.1070 *$ & & $-0.1226 * *$ & & $-0.1156^{* *}$ & \\
\hline P-value & & & & & 0.0655 & & 0.0537 & & 0.0321 & \\
\hline$R V I V$ & & & & & & 0.0140 & 0.0026 & 0.0026 & 0.0026 & 0.0031 \\
\hline P-value & & & & & & 0.1767 & 0.7749 & 0.7758 & 0.7798 & 0.7424 \\
\hline Size & 0.0003 & 0.0007 & 0.0003 & 0.0004 & 0.0006 & 0.0003 & 0.0006 & 0.0007 & 0.0007 & 0.0007 \\
\hline P-value & 0.9298 & 0.8187 & 0.9277 & 0.8878 & 0.8499 & 0.9179 & 0.8431 & 0.8234 & 0.8217 & 0.7989 \\
\hline B/M Ratio & $-0.0527 * * *$ & $-0.0531 * * *$ & $-0.0518 * * *$ & $-0.0520 * * *$ & $-0.0523 * * *$ & $-0.0515^{* * *}$ & $-0.0529 * * *$ & $-0.0530 * * *$ & $-0.0534 * * *$ & $-0.0531 * * *$ \\
\hline P-value & 0.0003 & 0.0002 & 0.0004 & 0.0004 & 0.0003 & 0.0004 & 0.0003 & 0.0003 & 0.0002 & 0.0003 \\
\hline Pre $1 M$ Return & -0.0008 & 0.0018 & -0.0018 & -0.0029 & 0.0000 & -0.0018 & 0.0064 & 0.0045 & 0.0060 & 0.0042 \\
\hline P-value & 0.9627 & 0.9139 & 0.9109 & 0.8568 & 0.9988 & 0.9125 & 0.7023 & 0.7929 & 0.7245 & 0.8036 \\
\hline Stock Volume & -0.0041 & -0.0046 & -0.0038 & -0.0043 & -0.0044 & -0.0055 & -0.0054 & -0.0055 & -0.0054 & -0.0054 \\
\hline P-value & 0.3731 & 0.3084 & 0.3987 & 0.3518 & 0.3293 & 0.1860 & 0.2013 & 0.1891 & 0.2087 & 0.2049 \\
\hline Market Beta & 0.0041 & 0.0050 & 0.0050 & 0.0051 & 0.0053 & 0.0055 & 0.0061 & 0.0063 & 0.0061 & 0.0064 \\
\hline P-value & 0.3465 & 0.2565 & 0.2544 & 0.2409 & 0.2328 & 0.2300 & 0.1890 & 0.1757 & 0.1861 & 0.1672 \\
\hline Bid-ask Spread & $-0.0620 *$ & $-0.0686 * *$ & $-0.0979 * * *$ & $-0.0999 * * *$ & $-0.1058 * * *$ & $-0.1019 * * *$ & $-0.0585^{*}$ & $-0.0587^{*}$ & $-0.0589 *$ & $-0.0606^{*}$ \\
\hline P-value & 0.0612 & 0.0446 & 0.0065 & 0.0057 & 0.0041 & 0.0050 & 0.0778 & 0.0774 & 0.0758 & 0.0706 \\
\hline Option Volume & $0.0242 *$ & $0.0245^{* *}$ & 0.0218 & $0.0239 *$ & $0.0238 *$ & $0.0261 * *$ & $0.0250 * *$ & $0.0246 * *$ & $0.0250 * *$ & $0.0256 * *$ \\
\hline P-value & 0.0587 & 0.0442 & 0.1030 & 0.0835 & 0.0624 & 0.0428 & 0.0434 & 0.0469 & 0.0334 & 0.0317 \\
\hline
\end{tabular}


Exhibit 7: Firm-Level Cross-Sectional Regression Results Over One-Week before the Crisis

Notes: Exhibit 7 presents the firm-level cross-sectional regression results for the intersection sample during the period before September 2008. The dependent variables are one-week returns on individual stocks after factor construction at the end of each calendar month. P-values are calculated using Newey-West method.

\begin{tabular}{|c|c|c|c|c|c|c|c|c|c|c|}
\hline & $\mathrm{I}$ & II & III & IV & $\mathrm{V}$ & VI & VII & VIII & IX & $\mathrm{X}$ \\
\hline Intercept & 0.0074 & 0.0066 & 0.0051 & 0.0047 & 0.0036 & 0.0030 & 0.0065 & 0.0058 & 0.0059 & 0.0057 \\
\hline P-value & 0.5760 & 0.6177 & 0.7050 & 0.7279 & 0.7846 & 0.8180 & 0.6171 & 0.6586 & 0.6473 & 0.6601 \\
\hline CPIV & $0.0862 * * *$ & & & & & & $0.0837 * * *$ & & $0.0939 * * *$ & \\
\hline P-value & 0.0000 & & & & & & 0.0001 & & 0.0000 & \\
\hline IVSKEW & & $-0.0450 * * *$ & & & & & & $-0.0628 * * *$ & & $-0.0498 * * *$ \\
\hline P-value & & 0.0000 & & & & & & 0.0000 & & 0.0000 \\
\hline$A M B$ & & & $-0.0157 *$ & & & & $-0.0272 *$ & $-0.0378 * * *$ & & \\
\hline P-value & & & 0.0848 & & & & 0.0541 & 0.0008 & & \\
\hline COMA & & & & -0.0101 & & & $0.0469 *$ & $0.0466 *$ & 0.0227 & -0.0032 \\
\hline P-value & & & & 0.6539 & & & 0.0764 & 0.0781 & 0.3358 & 0.8921 \\
\hline POMA & & & & & -0.0155 & & $-0.0453^{* *}$ & & $-0.0246 *$ & \\
\hline P-value & & & & & 0.3135 & & 0.0184 & & 0.0975 & \\
\hline$R V I V$ & & & & & & -0.0062 & $-0.0082^{* *}$ & $-0.0078 * *$ & $-0.0079 * *$ & $-0.0073^{*}$ \\
\hline P-value & & & & & & 0.1295 & 0.0401 & 0.0497 & 0.0447 & 0.0657 \\
\hline Size & 0.0001 & 0.0002 & 0.0001 & 0.0002 & 0.0003 & 0.0003 & 0.0001 & 0.0001 & 0.0002 & 0.0002 \\
\hline P-value & 0.8971 & 0.7619 & 0.8893 & 0.8013 & 0.7098 & 0.7382 & 0.9028 & 0.8591 & 0.8267 & 0.7878 \\
\hline B/M Ratio & $-0.0068^{* *}$ & $-0.0064^{* *}$ & $-0.0059 *$ & $-0.0059 *$ & $-0.0057 *$ & $-0.0060 *$ & $-0.0061^{*}$ & $-0.0060 *$ & $-0.0061^{*}$ & $-0.0059 *$ \\
\hline P-value & 0.0354 & 0.0458 & 0.0659 & 0.0736 & 0.0772 & 0.0587 & 0.0745 & 0.0753 & 0.0748 & 0.0733 \\
\hline Pre $1 M$ Return & -0.0027 & -0.0030 & -0.0029 & -0.0028 & -0.0026 & -0.0018 & 0.0006 & -0.0001 & 0.0008 & 0.0002 \\
\hline P-value & 0.6359 & 0.5910 & 0.6131 & 0.6208 & 0.6466 & 0.7423 & 0.9086 & 0.9819 & 0.8880 & 0.9685 \\
\hline Stock Volume & -0.0007 & -0.0007 & 0.0004 & 0.0001 & 0.0000 & 0.0010 & 0.0010 & 0.0012 & 0.0009 & 0.0011 \\
\hline P-value & 0.6713 & 0.6747 & 0.8244 & 0.9317 & 0.9903 & 0.5177 & 0.4911 & 0.4208 & 0.5471 & 0.4681 \\
\hline Market Beta & 0.0000 & 0.0002 & 0.0000 & 0.0000 & 0.0002 & 0.0005 & 0.0006 & 0.0005 & 0.0006 & 0.0005 \\
\hline P-value & 0.9823 & 0.8920 & 0.9781 & 0.9882 & 0.8903 & 0.7433 & 0.7099 & 0.7276 & 0.7260 & 0.7366 \\
\hline Bid-ask Spread & -0.0080 & -0.0078 & -0.0084 & -0.0082 & -0.0077 & -0.0083 & -0.0071 & -0.0067 & -0.0063 & -0.0070 \\
\hline P-value & 0.2786 & 0.3113 & 0.2525 & 0.2623 & 0.2851 & 0.2374 & 0.3195 & 0.3584 & 0.3730 & 0.3411 \\
\hline Option Volume & -0.0017 & -0.0009 & -0.0050 & -0.0043 & -0.0041 & -0.0064 & -0.0058 & -0.0055 & -0.0057 & -0.0050 \\
\hline P-value & 0.6965 & 0.8393 & 0.2973 & 0.3184 & 0.3527 & 0.1426 & 0.1422 & 0.1841 & 0.1428 & 0.2118 \\
\hline
\end{tabular}


Exhibit 8: Firm-Level Cross-Sectional Regression Results Over One-Week after the Crisis

Notes: Exhibit 8 presents the firm-level cross-sectional regression results for the intersection sample during the period after September 2008. The dependent variables are one-week returns on individual stocks after factor construction at the end of each calendar month. P-values are calculated using Newey-West method.

\begin{tabular}{|c|c|c|c|c|c|c|c|c|c|c|}
\hline & I & II & III & IV & $\mathrm{V}$ & VI & VII & VIII & IX & $\mathrm{X}$ \\
\hline Intercept & -0.0003 & -0.0008 & 0.0041 & 0.0029 & 0.0054 & -0.0013 & -0.0040 & -0.0036 & -0.0023 & -0.0031 \\
\hline P-value & 0.9845 & 0.9583 & 0.7984 & 0.8580 & 0.7382 & 0.9355 & 0.7948 & 0.8107 & 0.8801 & 0.8377 \\
\hline CPIV & $0.0378 * *$ & & & & & & 0.0184 & & 0.0314 & \\
\hline P-value & 0.0344 & & & & & & 0.3492 & & 0.1203 & \\
\hline IVSKEW & & $-0.0353 * *$ & & & & & & $-0.0375^{* *}$ & & $-0.0378 * *$ \\
\hline P-value & & 0.0319 & & & & & & 0.0191 & & 0.0182 \\
\hline$A M B$ & & & -0.0126 & & & & $-0.0211^{* *}$ & -0.0126 & & \\
\hline P-value & & & 0.1168 & & & & 0.0228 & 0.1380 & & \\
\hline COMA & & & & -0.0278 & & & -0.0305 & -0.0061 & -0.0511 & -0.0308 \\
\hline P-value & & & & 0.4616 & & & 0.4762 & 0.8817 & 0.2205 & 0.4064 \\
\hline POMA & & & & & -0.0229 & & $-0.0697 * * *$ & & $-0.0503 * * *$ & \\
\hline P-value & & & & & 0.2589 & & 0.0005 & & 0.0072 & \\
\hline$R V I V$ & & & & & & -0.0032 & -0.0037 & -0.0039 & -0.0041 & -0.0042 \\
\hline P-value & & & & & & 0.5993 & 0.5523 & 0.5175 & 0.5031 & 0.4789 \\
\hline Size & 0.0002 & 0.0004 & -0.0001 & 0.0000 & -0.0001 & 0.0003 & 0.0004 & 0.0004 & 0.0004 & 0.0004 \\
\hline P-value & 0.8038 & 0.6873 & 0.8891 & 0.9614 & 0.9470 & 0.7602 & 0.5993 & 0.6398 & 0.6519 & 0.6296 \\
\hline B/M Ratio & 0.0027 & 0.0027 & 0.0024 & 0.0024 & 0.0024 & 0.0026 & 0.0023 & 0.0023 & 0.0023 & 0.0025 \\
\hline P-value & 0.1211 & 0.1321 & 0.1615 & 0.1752 & 0.1646 & 0.1517 & 0.2022 & 0.2149 & 0.2016 & 0.1693 \\
\hline Pre $1 M$ Return & 0.0011 & 0.0020 & 0.0006 & 0.0008 & 0.0017 & -0.0015 & -0.0010 & -0.0009 & -0.0003 & -0.0003 \\
\hline P-value & 0.8665 & 0.7564 & 0.9236 & 0.8995 & 0.7881 & 0.8218 & 0.8645 & 0.8880 & 0.9630 & 0.9607 \\
\hline Stock Volume & -0.0001 & -0.0002 & 0.0000 & 0.0001 & 0.0000 & 0.0000 & -0.0002 & -0.0002 & -0.0002 & -0.0002 \\
\hline P-value & 0.7944 & 0.6501 & 0.9356 & 0.8517 & 0.9925 & 0.9555 & 0.7243 & 0.7551 & 0.6951 & 0.6858 \\
\hline Market Beta & -0.0012 & -0.0012 & -0.0014 & -0.0016 & -0.0013 & -0.0006 & -0.0013 & -0.0013 & -0.0013 & -0.0013 \\
\hline P-value & 0.6011 & 0.6260 & 0.5742 & 0.5350 & 0.6321 & 0.8287 & 0.6997 & 0.6988 & 0.7015 & 0.7037 \\
\hline Bid-ask Spread & -0.0319 & -0.0286 & $-0.0440 * *$ & $-0.0450 * *$ & $-0.0462 * *$ & $-0.0462 * *$ & -0.0307 & -0.0265 & -0.0322 & -0.0285 \\
\hline P-value & 0.1646 & 0.2167 & 0.0208 & 0.0247 & 0.0180 & 0.0211 & 0.1718 & 0.2457 & 0.1617 & 0.2195 \\
\hline Option Volume & $0.0017^{*}$ & $0.0020^{*}$ & $0.0014^{*}$ & 0.0013 & 0.0016 & $0.0013^{*}$ & $0.0019 *$ & $0.0017^{*}$ & $0.0020^{*}$ & $0.0018 *$ \\
\hline P-value & 0.0516 & 0.0716 & 0.0946 & 0.1066 & 0.1032 & 0.0846 & 0.0629 & 0.0869 & 0.0572 & 0.0792 \\
\hline
\end{tabular}

